\title{
Evaluation of perianal fistulas with magnetic resonance imaging: Significance of T2-weighted BLADE sequence in disease diagnosis
}

\section{Perianal fistüllerin manyetik rezonans görüntüleme ile değerlendirilmesi: T2 ağırlıklı BLADE sekansının hastalık tanısında önemi}

\author{
Safiye Sanem Dereli Bulut ${ }^{1}$, Zakir Sakcı ${ }^{1}$
}

\begin{abstract}
Aim: Anatomical details of perianal fistulas can be revealed more clearly by $\mathrm{T} 2$-weighted (T2-W) periodically rotated overlapping parallel lines with enhanced reconstruction (BLADE) sequence during magnetic resonance imaging (MRI). This study aimed to compare the efficacy of the T2-W BLADE sequence and the T2-W turbo spin echo (TSE) sequence in diagnosing perianal fistula, as well as to compare the findings with the results obtained using the dynamic contrast-enhanced (DCE) T1-weighted (T1-W) sequence during routine pelvic MRI examination.

Methods: Ninety patients (male/female: 67/23) who had undergone pelvic MRI examination (1.5Tesla) for the prediagnosis of perianal fistula were included in this prospective study.

In addition to our routine pelvic MRI protocol, T2-W BLADE sequence imaging and T2-W TSE sequence imaging in the axial, sagittal, and coronal planes were performed. Using a three-stage scoring system, two radiologists independently compared the T2-W BLADE and T2-W TSE sequences with each other and then with the DCE T1-W sequence in terms of perianal fistula imaging. Statistical analysis was performed using a sample t-test and the Cronbach's $\alpha$ test.

Results: Compared with the T2-W TSE sequence, the T2-W BLADE sequence was associated with fewer ghosting artifacts, with higher overall image quality, and with clearer visualization of the anatomical details of perianal fistula $(p<0.05)$. Images with high anatomic details and contrast resolution were obtained using the T2-W BLADE sequence similar to those obtained using the DCE T1-W sequence $(\mathrm{p}<0.05)$.

Conclusion: On the basis of the reduced imaging time and on the higher image resolution, T2-W images can be obtained with the BLADE technique for the diagnosis of perianal fistula.
\end{abstract}

Keywords: Magnetic resonance imaging, perianal fistula, artifacts, T2-weighted sequence, BLADE technique

\section{Öz}

Amaç: Manyetik Rezonans Görüntüleme (MRG) ile perianal fistül teşhisinde, T2-ağırlıklı (A) BLADE sekansın etkinliğini, T2-A Turbo Spin Eko (TSE) sekans ile karşılaştırmak ve bulguları, rutin pelvik MRG incelemede Dinamik Kontrastlı (DCE) T1-A sekans görüntüleri ile karşılaştırmak.

Yöntemler: Perianal fistül ön tanısı ile pelvik MRG incelemesi (1,5 Tesla) yapılan toplam 90 hasta prospektif çalışmamıza dahil edildi. Rutin pelvik MRG protokolümüze, üç planda T2A BLADE sekansı ve T2A TSE sekansları da dahil edildi. Perianal fistül tanısında T2A BLADE sekans ve T2A TSE sekansların üstünlüguünü birbiriyle ve ardından üç aşamalı skorlama ile DCE T1A sekans ile karşılaştırıldı. Değerlendirme iki radyolog tarafindan, farklı zamanlarda ve birbirinden bağımsız olarak yapıldı. İstatistiksel analiz için Simple t-test ve Cronbach's Alpha testi kullanıldı.

Bulgular: Perianal fistül tanısında, T2A BLADE sekans ile T2A TSE sekansa göre daha kısa sürede ve artefaktlara daha az duyarlı, yüksek çözünürlüklü görüntüler elde edildi ( $p<0,05)$. T2A BLADE sekans ile DCE T1A sekansına benzer yüksek kontrast çözünürlüğü olan görüntüler elde edildi $(\mathrm{p}<0,05)$.

Sonuç: Daha kısa sürede ve yüksek çözünürlüklü görüntüler elde edebilmesi nedeniyle, perianal fistül tanısında T2A görüntüler BLADE tekniği ile elde edilebilir.

Anahtar kelimeler: Manyetik rezonans görüntüleme, perianal fistül, artefaktlar, T2 ağırlıklı sekans, BLADE tekniği
1 University of Health Sciences, Umraniye Training and Research Hospital, Department of Radiology, Istanbul, Turkey.

iD

SSDB:0000-0003-4593-6227

ZS: 0000-0002-5144-385

Ethics Committee Approval: This study was approved by the ethics committee of Umraniye Training and Research Hospital with an approval number of 21194-28.12.2016.

Etik Kurul Onayı: Bu çalışma Ümraniye Eğitim ve Araştırma Hastanesi Etik Kurulu tarafindan 2119428.12.2016 onay numarası ile onaylanmıştır.

Conflict of Interest: No conflict of interest was declared by the authors.

Çıkar Çatışması: Yazarlar çıkar çatışması bildirmemiștir.

Financial Disclosure: The authors declared that this study has received no financial support. Finansal Destek: Yazarlar bu çalışma için finansal destek almadıklarını beyan etmişlerdir.

Geliș Tarihi / Received: 18.02.2021

Kabul Tarihi / Accepted: 22.03.2021

Yayın Tarihi / Published: 01.04.202

Sorumlu yazar / Corresponding author:

Safiye Sanem Dereli Bulut

Adres/Address: University of Health Sciences, Umraniye Training and Research Hospital, Department of Radiology, 34688, Istanbul, Turkey. e-mail: ssanembulut@gmail.com

Tel/Phone: +905327763354

Fax: +902166327124

Copyright (C) ACEM 


\section{Introduction}

A perianal fistula is characterized by an inflammatory process; once it has formed, a perianal fistula adversely affects the surrounding areas in the anal canal [1-3]. Perianal fistulas can cause considerable morbidity, and the majority of patients unfortunately undergo multiple medical and surgical treatments, as perianal fistulas demonstrate treatment resistance and exhibit a high recurrence rate [3].

The type and extent of fistulas and the co-existing pathologies, along with their radiological classification based on magnetic resonance imaging (MRI) findings, are important. Therefore a treating physician could plan the appropriate medical and surgical interventions that promote complete healing and ultimately prevent recurrence [3].

While multiple imaging techniques, including fistulography and endocavitary ultrasonography, have been used to evaluate perianal fistulas, MRI remains to be the preferred imaging modality. T2-weighted (T2-W) MRI sequences have been recently found to be the best techniques in acquiring a detailed anatomical view of the pelvis when evaluating perianal fistulas, and they also allow for the assessment of the anal canal $[4,5]$. However, the susceptibility of T2-W MRI to motion artifacts related to respiratory, intestinal, or vascular pulsatility can obscure findings [5]. Different sequences have been developed to quickly acquire images and thereby reduce artifacts; these techniques include the HASTE and steady-state precession techniques [6]. In addition, a promising sequence called the PROPELLER (periodically rotated overlapping parallel lines with enhanced reconstruction) sequence was developed by Pipe in 1999 [7-11]. Meanwhile, the BLADE sequence is relatively insensitive to respiratory movements, enabling the correction of in-plane motion, rotation, and translation $[7,8]$.

This study aimed to compare the efficacy of the T2-W BLADE sequence with the T2-W TSE sequence in diagnosing perianal fistula, as well as to compare the findings with the results of DCE T1-W sequence in routine pelvic MRI. Our hypothesis was that the T2-W BLADE sequence could obtain images of higher quality within a reduced imaging duration.

\section{Material and methods}

\section{Patients}

Patients who had undergone pelvic MRI examination for perianal fistula pre-diagnosis from January 1, 2017 to August 1, 2017 were included in this prospective study.

Our inclusion criteria were as follows: presence of a discharge from the perianal fistula and antibiotherapy was not given within the last month. The exclusion criteria were as follows: a history of having perianal fistula operation in the last two months, having a contraindicated condition for MR examination (stent history, pacemaker history, and claustrophobia), and younger than 18 years old.

\section{Ethical consideration}

Approval from the concerned ethics committee was sought (No. 21194), and informed written consent was obtained from all the included patients. And all procedures performed in studies involving human participants were in accordance with the ethical standards of the institutional and/or national research committee and with the 1964 Helsinki Declaration and its later amendments or comparable ethical standards.

\section{MRI Protocol}

Pelvic MRI was performed in the supine position with a six-channel body coil in 1.5 Tesla MR (Magnetom Avanto; Siemens Healthcare, Erlangen, Germany). The pelvic MRI protocols used in our study are summarized in Table 1.

Since the anal canal is tilted forward, the field of view and the scan extent were defined using a sagittal T2-W single shot image with the center line running along the anal canal. Axial and coronal images were obtained relative to the long axis of the anal canal. No antiperistaltic agent was used in our study.

Table 1. Perianal fistula magnetic resonance (MR) sequence protocols for the study.

\begin{tabular}{|c|c|c|c|c|c|}
\hline \multirow[b]{2}{*}{ Parameters } & \multirow[b]{2}{*}{$\begin{array}{c}\text { T2-weighted } \\
\text { TSE }\end{array}$} & \multicolumn{3}{|c|}{ Routine pelvic MR sequences } & \multirow{2}{*}{$\begin{array}{c}\begin{array}{c}\text { Added } \\
\text { sequence }\end{array} \\
\text { T2- } \\
\text { weighted } \\
\text { BLADE }\end{array}$} \\
\hline & & $\begin{array}{c}\text { T1- } \\
\text { weighted } \\
\text { TSE }\end{array}$ & $\begin{array}{l}\text { DCE 3D } \\
\text { T1 vibe }\end{array}$ & $\begin{array}{c}\text { Diffusion-weighted } \\
\text { imaging } \\
\left.\text { (b:0, } 400,800 \mathrm{~s} / \mathrm{mm}^{2}\right)\end{array}$ & \\
\hline TR/TE (ms) & $6200 / 117$ & $557 / 18$ & $4,7 / 2,3$ & $6250 / 81$ & $4000 / 83$ \\
\hline FOV (mm) & 260 & 320 & 220 & 220 & 260 \\
\hline matrix & $256 \times 256$ & $352 \times 352$ & $256 \times 256$ & $96 \times 96$ & $256 \times 256$ \\
\hline ETL & - & - & - & - & 27 \\
\hline FA $\left({ }^{0}\right)$ & - & - & - & 10 & - \\
\hline $\begin{array}{l}\text { Slice } \\
\text { thickness/ } \\
\text { spacing }(\mathrm{mm})\end{array}$ & $4 / 1,2$ & & $4 / 0$ & $4 / 1$ & $4 / 1,2$ \\
\hline Fat saturation & yes & no & yes & yes & yes \\
\hline $\begin{array}{l}\text { Acquisition } \\
\text { time }\end{array}$ & $\begin{array}{c}3 \mathrm{~min} \\
52 \mathrm{~s}\end{array}$ & $\begin{array}{c}3 \mathrm{~min} \\
50 \mathrm{~s}\end{array}$ & $\begin{array}{c}5 \mathrm{~min} \\
18 \mathrm{~s}\end{array}$ & $\begin{array}{c}2 \min \\
13 \mathrm{~s}\end{array}$ & $2 \min 24 s$ \\
\hline
\end{tabular}

The DCE T1 3D vibe sequence was performed before 30, 60, and $120 \mathrm{~s}$ after the peripheral administration of $0.1 \mathrm{mmol} / \mathrm{kg}$ gadobutrol at a rate of $2 \mathrm{~mL} / \mathrm{s}$. T2-W TSE and T2-W BLADE sequences were obtained using the fat sat technique in the axial, coronal, and sagittal planes. (TR: time of repetition; TE: time of echo; FOV: field of view; ETL: echo train length; and FA: flip angle).

\section{Image Analysis}

Image datasets were transferred to a Picture Archiving and Communication System (PACS) workstation for analysis (Centricity® PACS; GE Healthcare, Milwaukee, WI, USA). The images were independently evaluated by two radiologists with six and eight years of experience in abdominal radiology, respectively.

Image evaluation was performed in three phases (Figure 1). In the first phase, T2-W BLADE and T2-W TSE sequences were compared with each other in terms of image quality: presence of artifacts (bowel or respiratory motion, ghosting artifacts, aliasing, and radial artifact) and visibility of anatomic details in the perianal region.

The presence of artifacts was scored as follows: $1=$ marked, $2=$ moderate, $3=$ mild, $4=$ minimal, and $5=$ absent.

Some structures were set as references in assessing the visibility of anatomical details. These anatomical structures were the sphincter complex, the levator ani-pelvic diaphragm, and the anatomical details of the ischioanal and ischiorectal fossa. The scoring was as follows: 1 = cannot be seen, 2 = blurry but visualized, $3=$ acceptable, $4=$ good, and $5=$ excellent.

In the second phase, the T2-W TSE and T2-W BLADE sequences were compared in terms of their ability to distinguish the fistula type. In this evaluation, the DCE T1-W sequence was taken as a reference.

Finally, both observers were asked about their preferred T2-W sequence and the reasons behind such a preference. We categorized these reasons as follows: reduction of artifacts, higher image quality, clearer anatomical details of the perianal region, and shorter acquisition time. 
Perianal fistula classification was made according to the St James's University Hospital classification [2, 3].

\section{Statistical Analysis}

The distribution of outcome categories was assessed using the Kolmogorov-Smirnov test. The Cronbach's $\alpha$ test was utilized to compare the performance of the T2-W sequences. Pvalues of $<0.05$ were considered statistically significant.

All statistical analyses were performed using the Statistical Package for the Social Sciences (SPSS) software (version 22.0; SPSS Inc., Chicago, IL, USA).

\section{Results}

\section{Patients}

A total of 90 patients (23 females and 67 males) aged 22-75 years (median age: 46 years) were included in this study. Fourteen of these patients had undergone perianal fistula surgery more than two months prior. The remaining 76 patients were newly diagnosed to have perianal fistula. In seven patients, the etiology of this condition was an inflammatory bowel disease. Eighty patients had clinical chronic pain caused by fissure and by hemorrhoids in the perianal region, and three of them had fecal incontinence.

The distribution of patients according to perinal fistula types is summarized in Table 2.

Table 2. The distribution of patients according to perianal fistula types.

\begin{tabular}{lc} 
Types of perianal fistula & Distribution of Perianal fistula types \\
\hline Type 1 & $62 \%$ \\
Type 2 & $7 \%$ \\
Type 3 & $14 \%$ \\
Type 4 & $8 \%$ \\
Type 5 & $9 \%$ \\
\hline
\end{tabular}

\section{Presence of Artifacts}

The amounts of aliasing and ghosting artifacts were significantly reduced in the T2-W BLADE sequence images relative to those in the T2-W TSE sequence images $(\mathrm{p}<0.05$; Cronbach's $\alpha$ : 0.87).

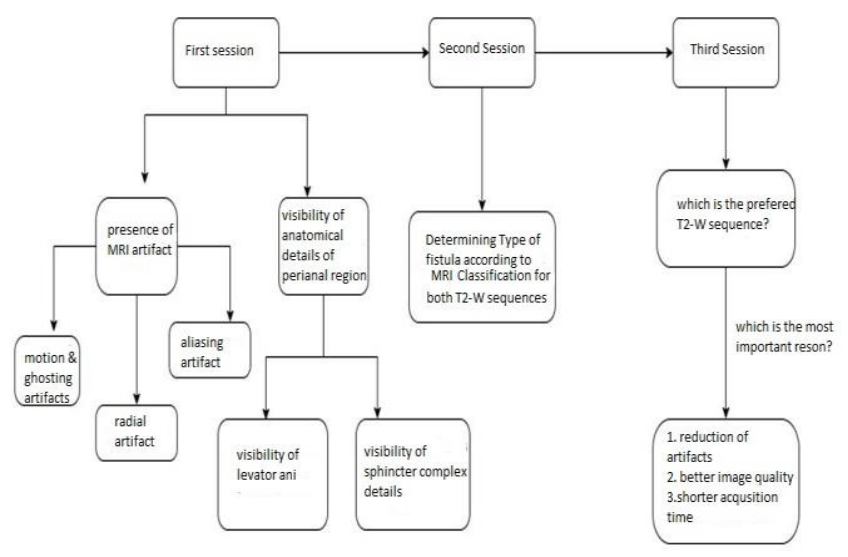

Figure 1. Flowchart showing the research methodology.

In terms of movement artifacts and radial artifacts, no significant difference was observed between the two sequences $(\mathrm{p}=0.07$; Cronbach's $\alpha: 0.65)$. The findings are detailed in Table 3.

\section{Visibility of Anatomical Features}

The sphincter anatomy and the levator ani were visualized more clearly with the T2-W BLADE sequence than with the T2-W TSE sequence ( $p<0.05$; Cronbach's $\alpha$ : 0.68) (Figures $2 \mathrm{a}$ and $2 \mathrm{~b}$ ).

No significant difference was observed between the two sequences in terms of the anatomical details of the ischioanal and ischiorectal fossa $(\mathrm{p}>0.05)$.

\section{Overall Image Quality}

Both observers found that the T2-W BLADE imaging was superior to the T2-W TSE imaging in terms of image quality $(\mathrm{p}<0.01$; Cronbach's $\alpha: 0.73)$ (Figure 3).

\section{Detection of Fistula Presence and Extension}

In the evaluation performed with DCE T1-W vibe images, no significant difference was found between the T2-W BLADE and T2-W TSE images in terms of fistula presence and type $(\mathrm{p}>0.05)$.

A complete consensus was reached between the two radiologists on the typing of perianal fistulas (Table 2).

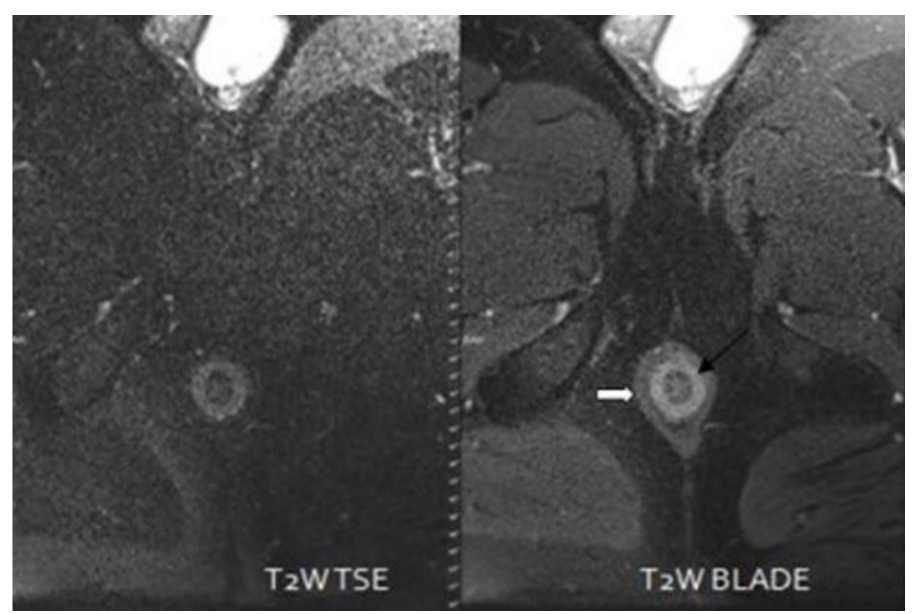

Figure 2a. Pelvic MRI image of a patient with chronic diarrhea by transverse plane fat-suppressed T2-weighted (T2-W) turbo spin echo (TSE) sequence and T2-W BLADE sequence.

A normal anatomy of the perianal region and the sphincter complex were observed. The perianal region found in the center of the image, as well as the internal sphincter (black arrow) and external sphincter (white arrow) forming the anal sphincter complex are clearly distinguishable in the T2W BLADE sequence.

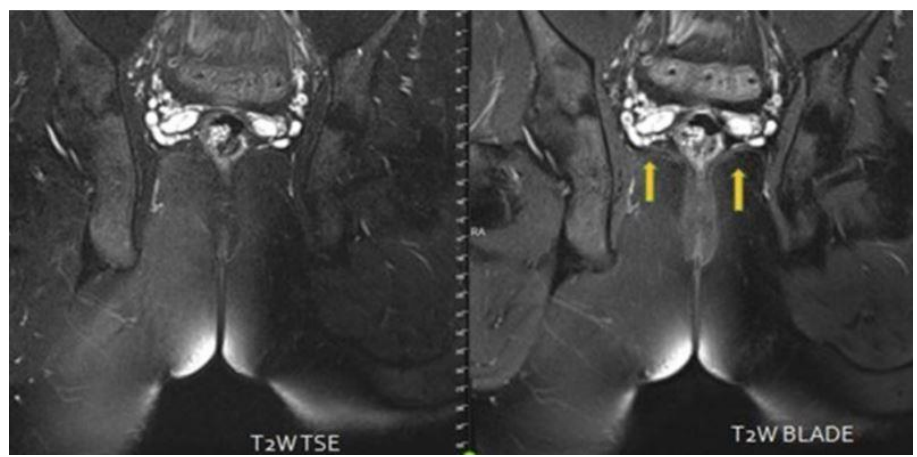

Figure $2 \mathrm{~b}$. Coronal plane of the T2-weighted (T2-W) turbo spin echo sequence and T2W BLADE sequence images of the same patient. Levator plates (thick yellow arrows), which are an essential landmark in fistula classification, are clearly distinguishable in the T2-W BLADE sequence image with a high-contrast resolution.

Levator plates (thick yellow arrows), which are an essential landmark in fistula classification, are clearly distinguishable in the T2-W BLADE sequence image with a high-contrast resolution.

\section{Preferred sequence}

Both observers preferred the T2-W BLADE sequence. The first reason was that the T2-W BLADE sequence required a shorter acquisition time than the T2-W TSE sequence (Cronbach's $\alpha$ : 0.74).

The second reason was the T2-W BLADE sequence's ability to reveal anatomical details of higher quality (Cronbach's $\alpha: 0.68)$. 


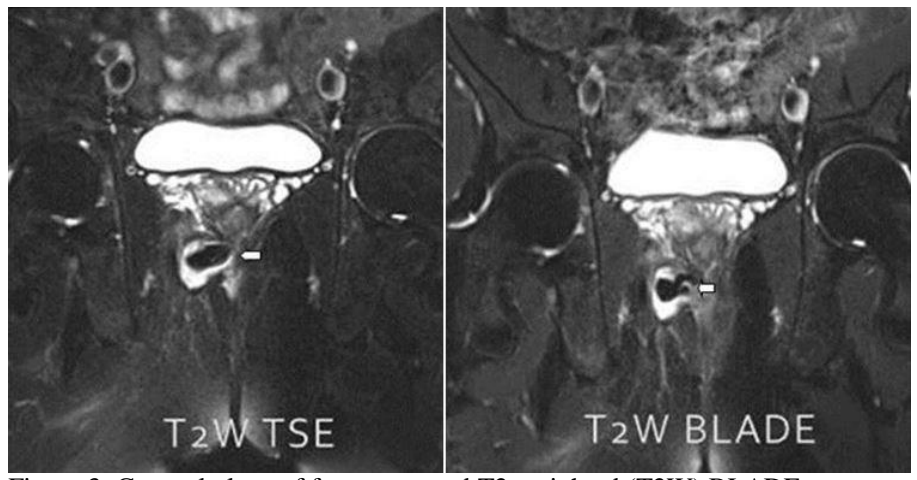

Figure 3: Coronal plane of fat-suppressed T2-weighted (T2W) BLADE sequence and T2W TSE images obtained from a 42-year-old man suffering from pain and discharge in the perianal region.

Grade 4 perianal fistula with abscess was noted according to the magnetic resonance classification of perianal fistulas. The correlation between abscess and fistula tract is more clearly seen in the T2W BLADE sequence than in the T2W TSE sequence. When looking at the free air in the fistula tract, it is noteworthy that two abscess-related fistulas were observed in the fistula tract.

Table 3. Average scores given by the observers.

\begin{tabular}{lcccc} 
& \multicolumn{5}{c}{ Average Scores } \\
\cline { 2 - 5 } & \multicolumn{2}{c}{ Observer 1 } & \multicolumn{2}{c}{ Observer 2 } \\
\cline { 2 - 5 } Presence of artifacts & $\begin{array}{c}\text { BLADE } \\
\text { (mean } \pm \text { SD) }\end{array}$ & $\begin{array}{c}\text { TSE } \\
\text { (mean } \pm \text { SD) }\end{array}$ & $\begin{array}{c}\text { BLADE } \\
(\text { mean } \pm \text { SD) }\end{array}$ & $\begin{array}{c}\text { TSE } \\
\text { (mean } \pm \text { SD) }\end{array}$ \\
\hline Motion & $4.96 \pm 0.18$ & $4.66 \pm 0.72$ & $4.92 \pm 0.26$ & $4.67 \pm 0.76$ \\
Aliasing & $4.95 \pm 0.20$ & $4.69 \pm 0.61$ & $4.98 \pm 0.10$ & $4.83 \pm 0.4$ \\
$\begin{array}{l}\text { Radial } \\
\text { Visibility of anatomical } \\
\text { features }\end{array}$ & $\begin{array}{c}4.98 \pm 0.10 \\
\text { BLADE }\end{array}$ & $\begin{array}{c}4.73 \pm 0.49 \\
\text { TSE }\end{array}$ & $\begin{array}{c}\text { BLADE } \\
\text { (mean } \pm \text { SD) }\end{array}$ & $\begin{array}{c}\text { (mean } \pm \text { SD) } \\
\text { Sphincter complex }\end{array}$ \\
$\begin{array}{l}\text { anatomy } \\
\text { Pelvic diaphragm } \\
\text { visibility }\end{array}$ & 5 & $2.92 \pm 0.27$ & 5 & $\begin{array}{c}\text { TSE } \\
\text { Details of ischioanal- }\end{array}$ \\
$\begin{array}{l}\text { ischiorectal fossa } \\
\text { Image quality }\end{array}$ & 5 & $2.94 \pm 0.27$ & 5 & $2.85 \pm 0.35$ \\
\hline
\end{tabular}

The table shows the average scores for T2W BLADE and T2W TSE sequences The presence of artifacts was scored for each of the following three categories: artifacts due to bowel or respiratory motion, artifacts due to aliasing, and presence radial artifact $(1=$ marked, $2=$ moderate, $3=$ mild, $4=$ minimal, and 5 $=$ absent $)$. Some structures were used as references in assessing the visibility of anatomical details. These anatomical structures were the sphincter complex (the visualization of internal and external sphincter), the levator ani-pelvic diaphragm, and the anatomical details of ischioanal and ischiorectal fossa $(1=$ not visible, 2 = blurry but visualized, 3 = acceptable, $4=$ good, and $5=$ excellent). The overall image quality was also assessed visually and scored as follows: $1=$ unacceptable, $2=$ poor, $3=$ average, $4=$ good, and $5=$ excellent .

Moreover, both observers preferred to employ the T2-W BLADE over the T2-W TSE in patients with a history of perianal fistula surgery and in patients who had grade 5 complex fistula.

In evaluating the co-existing pathologies in the ischioanal and ischiorectal fossa, both observers preferred the T2-W BLADE sequence in order to provide a more detailed assessment (Cronbach's $\alpha$ : 0.74).

\section{Discussion}

T2-W sequences are important in pelvic and abdominal MR imaging. However, because of their long acquisition time, they are susceptible to motion artifacts [5,6]. Compared with the other T2-W sequences, the T2-W BLADE sequence is promising for the reduction of motion artifacts that obscure important imaging findings as well as for the reduction of the time spent by patients in the scanner bed [7-11].

In this study, we compared the use of T2-W BLADE sequence and T2-W TSE sequence in patients with perianal fistulas. We found that the former produced images with fewer artifacts, with superior anatomical visualization, and with a higher image quality. Moreover, the fact that it shortens the imaging duration is beneficial in maintaining patient comfort.
Sequence duration was approximately 1 minute and 28 seconds shorter when performed with BLADE sequence.

Designed to compensate and correct for motion artifacts, the T2-W BLADE sequence is increasingly used as a respiratory-triggered sequence in non-compliant patients, including those who have difficulty performing breath-holding maneuvers $[10,11]$.

While the conventional T2-W TSE sequence techniques fill the k-field in a sequential fashion, the T2-W BLADE sequence fills the $\mathrm{k}$-field with radially oriented blades wherein the center of the k-field is further sampled, resulting in oversampling of the center of the k-space. This oversampling corrects phase, rotation, translation, and weighting to reduce spatial inconsistencies. Furthermore, redundancy in sampling can increase the signal-to-noise ratio, yielding higher quality images [7-9].

In the literature, such an advanced method as radial kspace sampling has been shown to reduce motion artifacts in different body regions [8-12]. For example, Lane et al. compared pelvic imaging using T2-W BLADE and T2-W TSE sequences in 26 female patients; they found that the T2-W BLADE was superior in evaluating the anatomy of the uterine junctional zone, in determining the contours of ovaries as well as in depicting follicles, and in detecting fibroids with fewer motion artifacts [12]. Although the T2-W BLADE technique may reduce motion artifacts due to factors such as patient motion and breathing, it may lead to streak artifacts (i.e., wrap-around and other types of aliasing artifacts) $[11,12]$

While we did not directly assess streak artifacts in our study, we did not experience any diagnostic issues related to streak artifacts given that our region of interest (i.e., the perianal region of the pelvis) was located in the center of the image rather than in the periphery where streak artifacts appear.

Another inherent issue in T2-W BLADE is the nonuniform weighting of $\mathrm{k}$-space data in the phase-encoding direction, which may lead to artifacts associated with signal nonuniformity $[8,9]$. However, we were not able to assess this issue in our study.

Sahnan et al. stated that the key to understanding the treatment options and the likelihood of their success is deciphering the exact morphology of the tract(s) and the amount of sphincter involved. They also used the T2-W BLADE sequence. They reported that they could easily reveal the anatomy of complex fistulas with the 3D images they created by marking the sphincter complex, the levator plate, and the fistula [13]. In our study, we evaluated the fistula anatomy in three planes. Similarly, we were able to obtain detailed anatomical information about the perianal fistula.

As reported in the literature, the use of endoanal coils to aid in the preoperative diagnosis and evaluation of perianal fistulas have been found inadequate compared with the use of phase sequence coils. In particular, supralevatoric and cutaneous extensions have not been clearly assessed. Moreover, it has been emphasized that endoanal coil application cannot be tolerated by some patients [14].

We obtained the BLADE sequence with the fat suppression technique. Thanks to the suppression of the surrounding fatty tissue in the perianal region, the required contrast for perianal fistula visibility has been increased [1-3, 13].

In our study, the T2-W BLADE sequence allowed for the easy visualization of the supralevator region, especially in coronal plane images. The fact that the imaging does not require any endocavitary application and that the imaging time required less than $25 \mathrm{~s}$ for each sequence would ensure patient comfort during the preoperative evaluation for perianal fistula. Another 
advantage of this sequence is that antiperistaltic agent was not used.

Our study has some limitations. Firstly, no quantitative measurements were performed to evaluate the T2 contrast of the sequences; instead, we qualitatively evaluated the overall quality of the images. Secondly, diagnosis of active fistula was made with reference to the high-contrast T1-W DCE VIBE sequence images and without reference to pathology. Thirdly, our patient sample consisted of adult patients only. However, we speculate that the T2-W BLADE sequence can be applied in the pediatric age group and may be especially useful for this group, who may have more difficulty in staying still and in holding their breath. Finally, the observers' interpretation of the T2-W BLADE and T2-W TSE images might have been biased as both types of images presented unique image characteristics.

In conclusion, our findings support that the T2-W BLADE is clinically promising for the diagnosis of perianal fistulas and that it offers substantial benefits, including reduced imaging time and significantly reduced ghosting and aliasing artifacts in the images. T2-W BLADE is promising as an important tool for improving the confidence of radiologists in assessing perianal fistulas as well as in yielding important information that will help a treating physician to determine the best medical or surgical treatment for patients.

\section{References}

1. Erden A. MRI of anal canal: normal anatomy, imaging protocol, and perianal fistulas: part 1. Abdom Radiol. 2018;43:1334-52.

2. De Miguel C J, del Salto LG, Rivas PF, del Hoyo LF, Velasco LG, de las Vacas MI, et al. MR imaging evaluation of perianal fistulas: spectrum of imaging features. Radiographics. 2012;32:175-94.

3. Choudhary J, Kaushal L, Rajput P. Role of Magnetic Resonance Imaging in Evaluation of Perianal Fistula. Int J Sci Stud. 2020;8:90-4.

4. Visscher AP, Felt-bersma RJ. Endoanal ultrasound in perianal fistulae and abscesses. Ultrasound Q. 2015;31:130-7.

5. Zand KR, Reinhold C, Haider MA, Nakai A, Rohoman L, Maheshwari S. Artifacts and pitfalls in MR imaging of the pelvis; J Magn Reson Imaging. 2007; 26:480-97.

6. Keogan MT, Edelman RR. Technologic advances in abdominal MR imaging. Radiology. 2001; 220:310-20.

7. Pandit P, Qi Y, King KF, Johnson GA. Reduction of artifacts in T2 -weighted PROPELLER in high-field preclinical imaging. Magn Reson Med. 2011;65:538-43.

8. Hirokawa Y, Isoda H, Maetani YS, Arizono S, Shimada K, Togashi K. Evaluation of motion correction effect and image quality with the periodically rotated overlapping parallel lines with enhanced reconstruction (PROPELLER) (BLADE) and parallel imaging acquisition technique in the upper abdomen. $\mathrm{J}$ Magn Reson Imaging. 2008;28:957-62.

9. Tamhane AA, Arfanakis K. Motion correction in periodicallyrotated overlapping parallel lines with enhanced reconstruction ( PROPELLER ) and turboprop MRI. Magn Reson Med. 2009;62:174-82.

10. Ciet P, Serra G, Bertolo S, et al. Assessment of CF lung disease using motion corrected PROPELLER MRI: a comparison with CT. Eur Radiol. 2016;26:780-7.

11. Ohgiya Y, Suyama J, Seino N, Spronk S, Ros M, Fraioli F, et al. MRI of the Neck at 3 Tesla Using the Periodically Rotated Overlapping Parallel Lines with Enhanced Reconstruction (PROPELLER) (BLADE) Sequence Compared with T2-Weighted Fast Spin-Echo Sequence. J. Magn. Reson. Imaging 2010;32:1061-1067.

12. Lane BF, Vandermeer FQ, Oz RC, Irwin EW, McMillan AB, Wong-You-Cheong JJ. Comparison of sagittal T2-weighted BLADE and fast spin-echo MRI of the female pelvis for motion artifact and lesion detection. AJR Am J Roentgenol. 2011;197: $\underline{\text { W307-13. }}$.
13. Sahnan K, Adegbola SO, Tozer PJ, Patel U, Ilangovan R, Warusavitarne $\mathrm{J}$, et al. Innovation in the imaging perianal fistula: a step towards personalised medicine. Therap Adv Gastroenterol. 2018;11:1756284818775060.

14. Almeida IS, Jayarajah U, Wickramasinghe DP, Samarasekera DN. Value of three-dimensional endoanal ultrasound scan (3DEAUS) in preoperative assessment of fistula-in-ano. BMC Res Notes. 2019;12:66. 